\title{
Pulley torsional vibration damper characterization
}

\author{
Lionel Manin ${ }^{1, a}$, RÉgis Dufour ${ }^{1}$ and SÉbastien Schultz ${ }^{2}$ \\ 1 Université de Lyon, CNRS, INSA-Lyon, LaMCoS UMR 5259, 69621 Villeurbanne, France \\ 2 Automotive Division/Vehicle Service Market, 78180 Montigny-Le-Bretonneux, France
}

Received 30 November 2012, Accepted 16 April 2013

\begin{abstract}
The pulleys of an automotive front engine accessory drive are driven in rotation by a poly-V belt itself driven by the crankshaft pulley. This driving pulley is often used as a torsional vibration damper (TVD) for the crankshaft. Three elements compose the pulley: the hub, a rubber ring and an inertia steel ring with v-ribs on its outer diameter. Although the crankshaft torsional vibrations are dampen, they are transmitted to the belt transmission and therefore to the driven accessories. Hence, recent developments have conducted to add a decoupling function to these pulleys. The decoupling is realized by an other rubber ring. The TVD pulley components are designed in order to dampen crankshaft vibrations over a given frequency range, i.e. stiffness and damping characteristics are determined for the rubber ring. These expected characteristics have to be checked after manufacturing for product certification but also to give some real measured data input for simulation models. An experimental characterization method is presented and discussed for the determination of the stiffness and damping coefficients of the rubber rings used in such pulley. The test rig developed is temperature controlled in order to show the influence of the temperature.
\end{abstract}

Key words: Characterization / stiffness / damping / TVD pull

\section{Introduction}

Automotive engines and especially diesel engines when firing produce torsional crankshaft vibrations. These vibrations are partly due to the cyclic rod forces working on the crankshaft combined with its proper rotation; it results in a non constant rotation speed. These torsional vibrations could lead to excessive bearing wear, accessory belt wear and/or noise and transverse belt vibrations. Hence it is important to dampen them. One classical way to do this is to use a dual mass flywheel; another way is to use a Torsional Vibration Damper (TVD) crankshaft pulley. The principle is to separate in two the crankshaft pulley and to insert a rubber ring between the two metal parts (Fig. 1), a vibration absorber is therefore obtained. There are two types of TVD pulley, single or dual mass rubber (Figs. 2, 3).

By adding a decoupling feature to the standard damper, the accessory belt drive can be isolated from the crankshaft vibrations, it also reduces the cyclic speed variation in the low speed range. This is shown in Figure 3 by the connecting rubber between the hub and the pulley.

The design of TVD pulleys is well known and the theory of such components is described in the literature [1]. The characterization of the belts has been studied and is reported in reference [2]. The main works that make

\footnotetext{
${ }^{a}$ Corresponding author: lionel.manin@insa-lyon.fr
}

\section{Nomenclature}

\begin{tabular}{|c|c|}
\hline$\overline{f_{1,2}}$ & resonance frequency $(\mathrm{Hz})$ \\
\hline$k_{1,2}$ & torsion stiffness (N.m.s/rad) \\
\hline$k_{1,2 \mathrm{~m}}$ & mean value of torsion stiffness (N.m.s/rad) \\
\hline$c_{1,2}$ & torsion damping coefficient (N.m.s/rad) \\
\hline$c_{1,2 \mathrm{~m}}$ & $\begin{array}{l}\text { mean value of torsion damping coefficient } \\
\text { (N.m.s/rad) }\end{array}$ \\
\hline$\alpha_{1,2}$ & viscous damping ratio \\
\hline$\Delta f$ & frecency bandwith $(\mathrm{Hz})$ \\
\hline$I_{1,2}$ & torsion inertia $\left(\mathrm{kg} \cdot \mathrm{m}^{2}\right)$ \\
\hline
\end{tabular}

reference about the dynamics of accessory belt drive do not consider TVD pulley [3-5]. This paper aims at giving some simple and easy to implement methods for determining TVD pulley characteristics that might be used as input for simulation model or as value to check the design.

\section{Characterization}

\subsection{Test description}

The pulley is clamped to a rigid frame as shown in Figure 4, the hub is fastened to the frame. Accelerometers are glued on to the additional mass and to the pulley so that they are sensitive to the rotational acceleration, i.e.; 


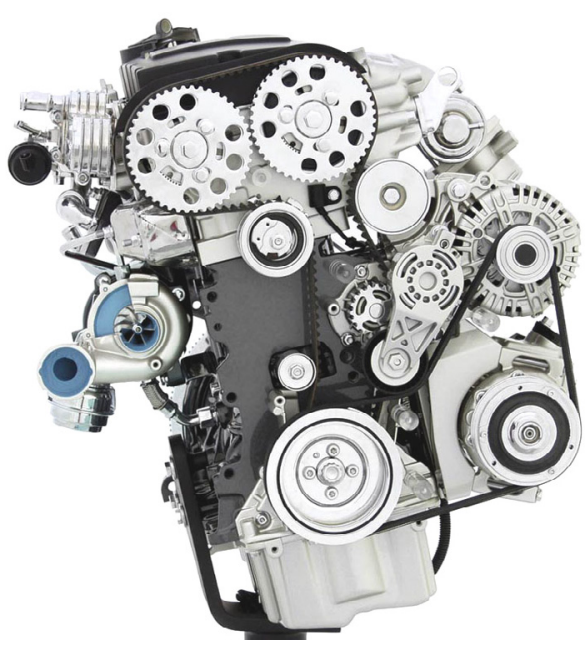

Fig. 1. FEAD with TVD crankshaft pulley.

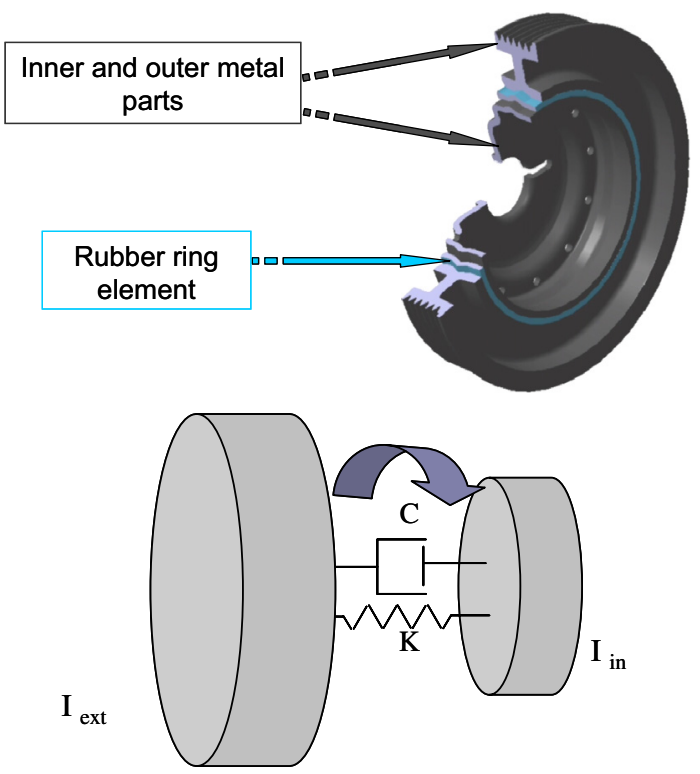

Fig. 2. TVD pulley with its dynamic model.

the torsional response of the system subjected to a torsion excitation by mean of a tangent force applied by a shaker. Then two types of test are performed:

a) to determine $k_{1}$ and $c_{1}$, the pulley is excited with a shaker. A sine sweep excitation is realized at low frequency from $30 \mathrm{~Hz}$ to $70 \mathrm{~Hz}$. The frequency response function $(\mathrm{FRF})$ of the pulley accelerometer permits to identify the resonance frequency $f_{1}$ and its associated damping ratio $\alpha_{1}$ from the bandwidth value for an attenuation of $3 \mathrm{~dB}$ (Fig. 7).

$$
\begin{aligned}
f_{1} & =\frac{1}{2 \pi} \sqrt{\frac{k_{1}}{I_{1}}} \rightarrow \quad k_{1}=4 \pi^{2} f_{1}^{2} I_{1} \\
\alpha_{1} & =\frac{\Delta f(-3 \mathrm{~dB})}{2 f_{1}} \rightarrow c_{1}=4 \alpha_{1} I_{1} \pi f_{1}
\end{aligned}
$$

b) to determine $k_{2}$ and $c_{2}$, the additional mass ring is excited with a shaker. A sine sweep excitation is
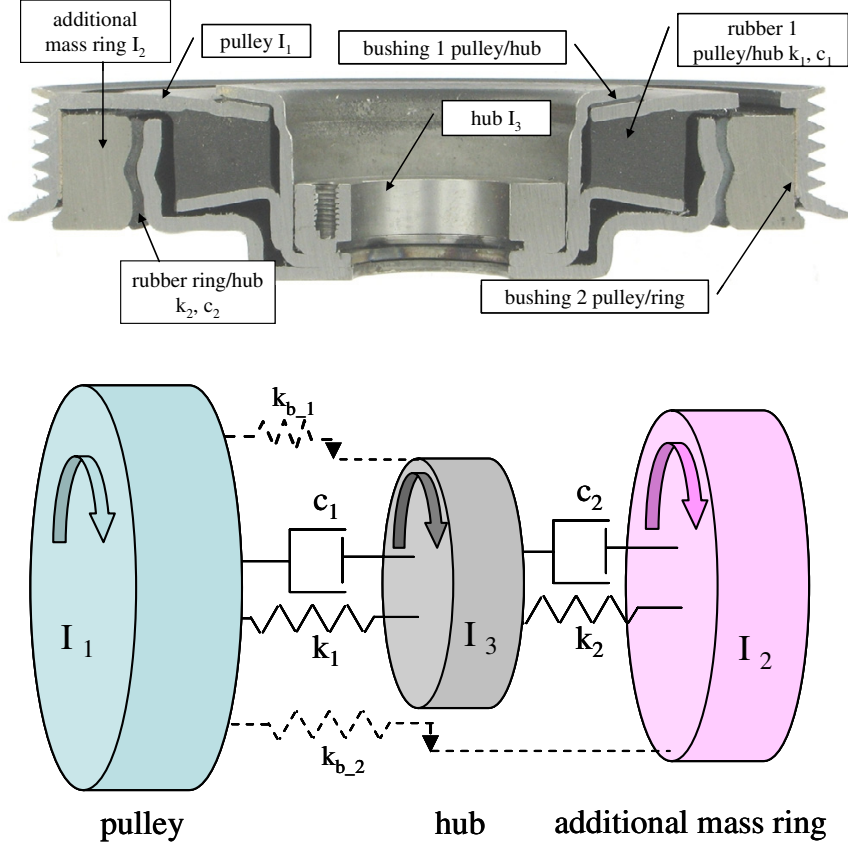

Fig. 3. Dual-mass rubber TVD crankshaft pulley and its torsional vibration model.

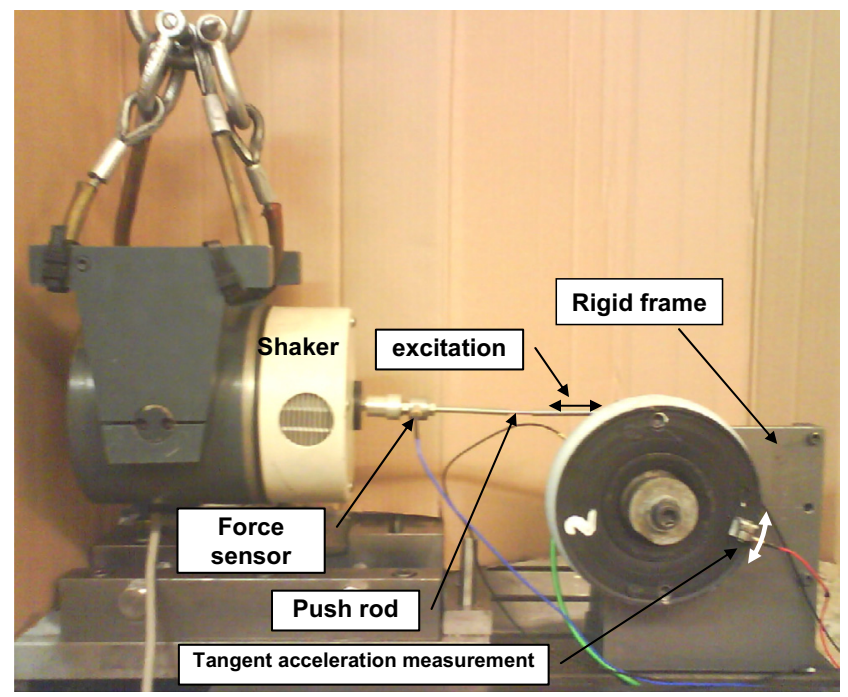

Fig. 4. Characterization test rig.

performed from $200 \mathrm{~Hz}$ to $450 \mathrm{~Hz}$. The frequency response function (FRF) of the additional mass accelerometer permits to identify the resonance frequency $f_{2}$ and its associated damping ratio $\alpha_{2}$ (Fig. 8).

$$
\begin{aligned}
f_{2} & =\frac{1}{2 \pi} \sqrt{\frac{k_{2}}{I_{2}}} \rightarrow \quad k_{2}=4 \pi^{2} f_{2}^{2} I_{2} \\
\alpha_{2} & =\frac{\Delta f(-3 \mathrm{~dB})}{2 f_{2}} \rightarrow c_{2}=4 \alpha_{2} I_{2} \pi f_{2}
\end{aligned}
$$

The excitation is applied to the pulley or to the additional mass via a shaker (Gearing and Watson GWV20) and with a connecting screw (Figs. 5a, 5b). The excitation 


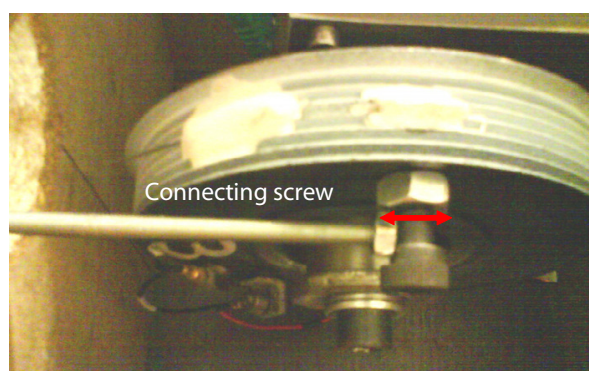

(a) Pulley excitation, connecting screw

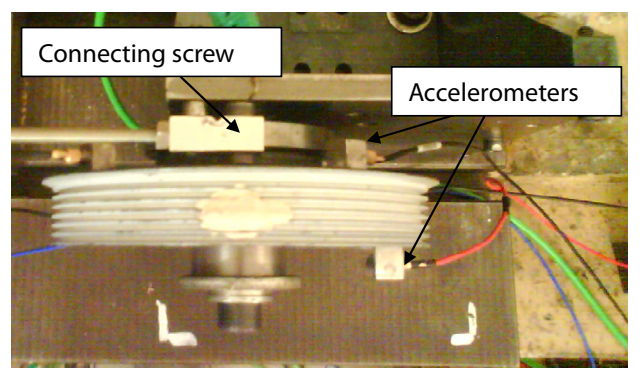

(b) Additional mass ring excitation, accelerometers

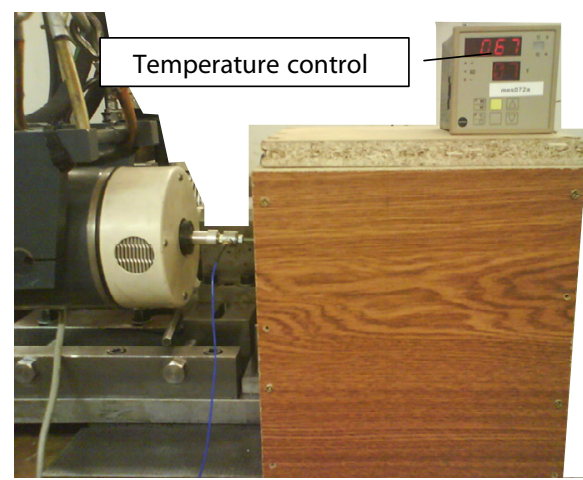

(c) Temperature controlled box

Fig. 5. Detailed views of the test rig.

force is measured using a piezoelectric force sensor (Dytran 1051V2), the angular acceleration is measured with accelerometers (BK 4507B, Dytran 3220B) that are glued on the pulley and on the additional mass ring.

In order to determine the influence of the temperature, the tests are realized at several temperatures. A box made of wood is encapsulating the pulley and the rigid frame. The temperature of the pulley is controlled with a thermocouple; the box is heated with a hot air blower (Leister, hot wind system), (Figs. 5c, 5d).

The torsion excitation of the pulley is realized by the sine transverse force excitation applied by the shaker. The accelerometers are glued such that the direction of measurement is tangent to the pulley rotation. Hence the translation acceleration measured corresponds to the angular acceleration multiplied by the distance between the accelerometer and the pulley center.

The inertias $\left(I_{1}\right.$ and $\left.I_{2}\right)$ of the metal parts that constitute the pulleys are known from the pulley datasheet. However, if it is not the case, they can be determined experimentally by measurements. First the pulley mass is measured, then the dimensions are measured on a cut pulley (Fig. 3). Using these dimensions, a CAD model is realized (Fig. 6). The comparison between the measured mass and the estimated mass from the CAD model permits to define a factor of proportionality, then the inertias of the pulley components calculated from the CAD model are corrected by this factor (Tab. 1).

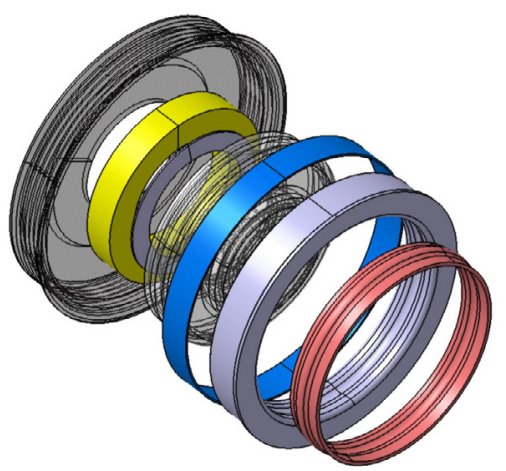

Fig. 6. Exploded $3 \mathrm{D}$ view of the CAD model.

\subsection{Measurement results}

\subsubsection{Pulley decoupling rubber, $k_{1}$ and $c_{1}$}

As it can be observed in Figure 7 , the FRF of the pulley $I_{1}$ shows a resonance peak at $52 \mathrm{~Hz}$ for a characterization temperature of $20{ }^{\circ} \mathrm{C}$. When the temperature increases, the resonance is much less obvious. Three samples of pulley have been tested, a good reproducibility was observed (Tab. 2). The mean values of torsional stiffness and viscous damping coefficient $k_{1 m}$ and $c_{1 m}$ are calculated from the values obtained for each sample pulley. For the temperatures higher than $20^{\circ} \mathrm{C}$ it was not possible to determine the damping ratio with the bandwidth 

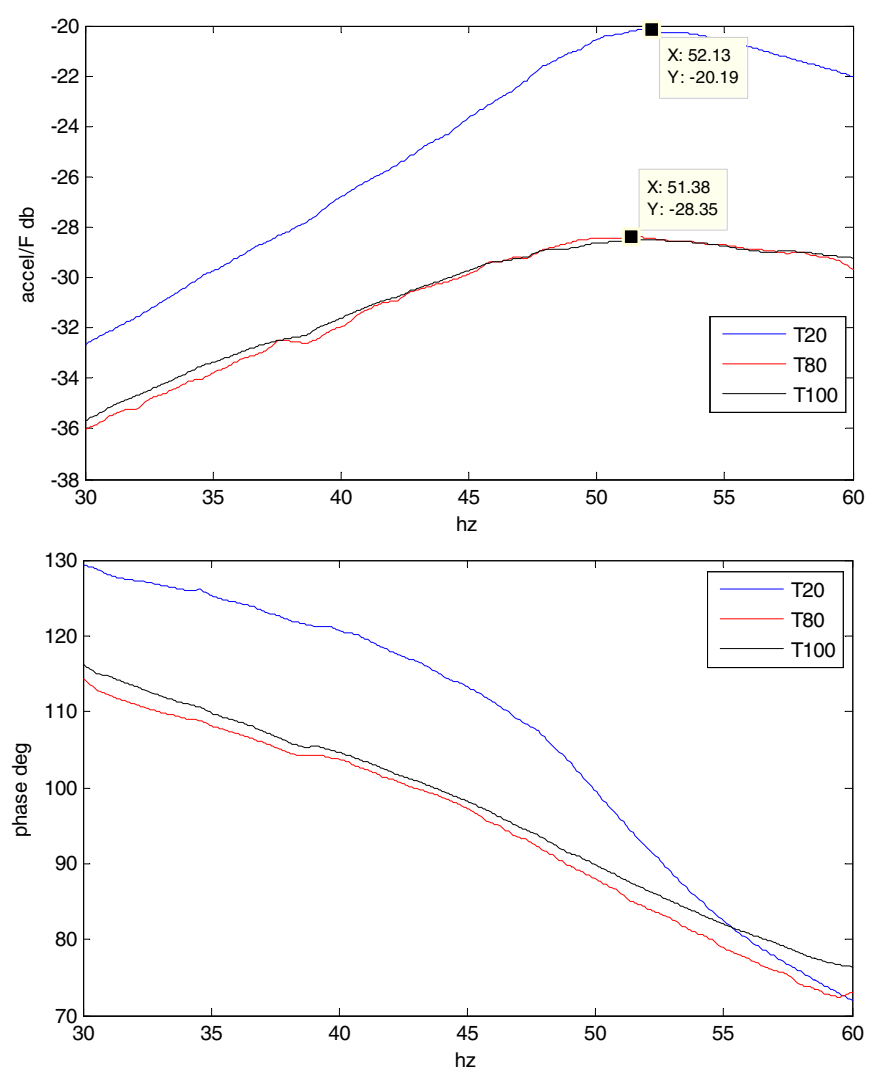

Fig. 7. Pulley FRF and phase at three different temperatures for pulley excitation.

Table 1. Inertias of pulley components.

\begin{tabular}{|c|c|c|c|}
\hline & Pulley 1 & Pulley 2 & Pulley 3 \\
\hline Measured mass (g) & 2310 & 2320 & 2320 \\
\hline CAD mass (g) & 2420 & 2420 & 2420 \\
\hline CAD inertia (kg.m ${ }^{2}$ ) & & & \\
\hline Pulley & $2.76 \mathrm{E}-03$ & & \\
\hline Additional mass & $3.25 \mathrm{E}-03$ & & \\
\hline Hub & $1.18 \mathrm{E}-03$ & & \\
\hline Corrected inertia & & & \\
\hline Pulley & $2.63 \mathrm{E}-03$ & $2.65 \mathrm{E}-03$ & $2.65 \mathrm{E}-03$ \\
\hline Additional mass & $3.10 \mathrm{E}-03$ & $3.12 \mathrm{E}-03$ & $3.12 \mathrm{E}-03$ \\
\hline Hub & $1.13 \mathrm{E}-03$ & $1.13 \mathrm{E}-03$ & $1.13 \mathrm{E}-03$ \\
\hline
\end{tabular}

method due to a too flat FRF around the resonance frequency which peak amplitude was attenuated. It appears that the stiffness decreases with the increase of temperature which is consistent with the decrease of the Young modulus for a rubber.

\subsubsection{Additional mass ring rubber, $k_{2}$ and $c_{2}$}

The same three pulley samples have been tested. The torsion excitation is realized by subjecting the additional mass ring to a sine sweep force excitation tangent to the
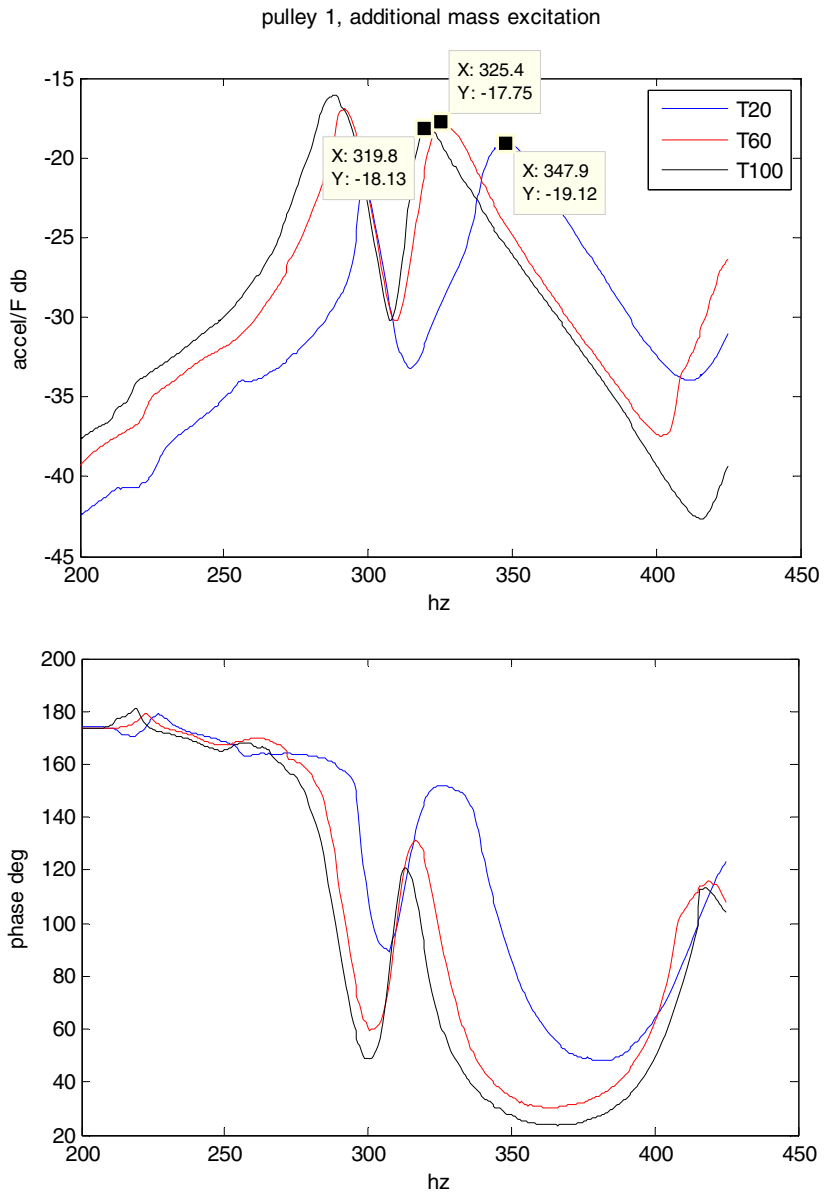

Fig. 8. FRF and phase of accelerometer signal at three different temperatures for additional mass ring excitation.

pulley, from $200 \mathrm{~Hz}$ to $450 \mathrm{~Hz}$ (Fig. 5b). Two resonance peaks can be seen on the FRF represented in Figure 8. The peak on the right corresponds to the additional mass ring rubber resonance frequency; it is used to determine the values of $k_{2}$ and $c_{2}$ according to equations (3) and (4). The results and the mean values, $k_{2 m}$ and $c_{2 m}$, are listed in Table 3. The second peak on the left corresponds to the resonance of the additional mass coupled with the pulley, i.e. the two rubber rings add their stiffness and damping, the pulley-hub bushing also plays a role.

It can be observed from Table 3 that the stiffness $k_{2 m}$ decreases with the increase of temperature which probably makes the rubber softer. One can also suspect that the friction in the bushing 2 is decreasing with the increase of temperature, therefore the damping should decrease also. The three tested pulleys show the same behavior and have similar stiffness and damping coefficients.

Knowing the stiffness $k_{2}$ and $k_{1}$ from the previous analyses it is also possible to estimate the stiffness of the bushing $1 k_{\mathrm{b} 1}$ from the left peak frequency (see, Eqs. (5), (6)).

$$
\begin{aligned}
f_{1+2} & =\frac{1}{2 \pi} \sqrt{\frac{k_{2}+k_{1}+k_{b 1}}{I_{2}+I_{1}}} \\
k_{b 1} & =4 \pi^{2} f_{1+2}^{2}\left(I_{2}+I_{1}\right)\left(k_{2}+k_{1}\right)
\end{aligned}
$$


Table 2. Resonance frequencies, stiffness and damping coefficients of the pulley mass rubber for the three pulley samples tested at three different temperatures.

\begin{tabular}{|c|c|c|c|c|c|c|}
\hline Pulley sample & $T=$ & $0{ }^{\circ} \mathrm{C}$ & & $=60{ }^{\circ} \mathrm{C}$ & & $=100{ }^{\circ} \mathrm{C}$ \\
\hline & $f_{1} \mathrm{~Hz}$ & $k_{1}(\mathrm{~N} . \mathrm{m} / \mathrm{rad})$ & $f_{1} \mathrm{~Hz}$ & $k_{1}(\mathrm{~N} \cdot \mathrm{m} / \mathrm{rad})$ & $f_{1} \mathrm{~Hz}$ & $k_{1}(\mathrm{~N} \cdot \mathrm{m} / \mathrm{rad})$ \\
\hline 1 & 52.1 & $2.82 \mathrm{E}+02$ & 51.4 & $2.75 \mathrm{E}+02$ & 51.4 & $2.75 \mathrm{E}+02$ \\
\hline 2 & 50.4 & $2.65 \mathrm{E}+02$ & 50.3 & $2.64 \mathrm{E}+02$ & 50.3 & $2.64 \mathrm{E}+02$ \\
\hline 3 & 53.7 & $3.01 \mathrm{E}+02$ & 51.23 & $2.74 \mathrm{E}+02$ & 51.08 & $2.73 \mathrm{E}+02$ \\
\hline & $k_{1 \mathrm{~m}}$ & $2.83 \mathrm{E}+02$ & $k_{1 \mathrm{~m}}$ & $2.71 \mathrm{E}+02$ & $k_{1 \mathrm{~m}}$ & $2.71 \mathrm{E}+02$ \\
\hline & $d F(-3 \mathrm{~dB}) \mathrm{Hz}$ & $c_{1}$ (N.m.s/rad) & \multirow{4}{*}{\multicolumn{2}{|c|}{ Not measurable }} & \multirow{4}{*}{\multicolumn{2}{|c|}{ Not measurable }} \\
\hline 1 & 20 & 0.33 & & & & \\
\hline 2 & \multicolumn{2}{|c|}{ Not measurable } & & & & \\
\hline \multirow[t]{2}{*}{3} & 25 & 0.42 & & & & \\
\hline & $c_{1 \mathrm{~m}}$ & 0.37 & & & & \\
\hline
\end{tabular}

Table 3. Resonance frequencies, stiffness and damping coefficients of the additional mass rubber for the three pulleys tested at three different temperatures.

\begin{tabular}{|c|c|c|c|c|c|c|}
\hline \multirow[t]{2}{*}{ Pulley sample } & \multicolumn{2}{|c|}{$T=20^{\circ} \mathrm{C}$} & \multicolumn{2}{|c|}{$T=60{ }^{\circ} \mathrm{C}$} & \multicolumn{2}{|c|}{$T=100{ }^{\circ} \mathrm{C}$} \\
\hline & $f_{2} \mathrm{~Hz}$ & $k_{2}(\mathrm{~N} . \mathrm{m} / \mathrm{rad})$ & $f_{2} \mathrm{~Hz}$ & $k_{2}($ N.m/rad $)$ & $f_{2} \mathrm{~Hz}$ & $k_{2}(\mathrm{~N} . \mathrm{m} / \mathrm{rad})$ \\
\hline 1 & 348.5 & $1.49 \mathrm{E}+04$ & 325.4 & $1.30 \mathrm{E}+04$ & 319.8 & $1.25 \mathrm{E}+04$ \\
\hline 2 & 359.8 & $1.59 \mathrm{E}+04$ & 335.6 & $1.39 \mathrm{E}+04$ & 329.9 & $1.34 \mathrm{E}+04$ \\
\hline 3 & 340.6 & $1.43 \mathrm{E}+04$ & 327.7 & $1.32 \mathrm{E}+04$ & 321.5 & $1.27 \mathrm{E}+04$ \\
\hline & $k_{2 \mathrm{~m}}$ & $1.50 \mathrm{E}+04$ & $k_{2 \mathrm{~m}}$ & $1.33 \mathrm{E}+04$ & $k_{2 \mathrm{~m}}$ & $1.29 \mathrm{E}+04$ \\
\hline & $d F(-3 \mathrm{~dB}) \mathrm{Hz}$ & $c_{2}($ N.m.s/rad $)$ & $d F(-3 \mathrm{~dB}) \mathrm{Hz}$ & $c_{2}$ (N.m.s/rad) & $d F(-3 \mathrm{~dB}) \mathrm{Hz}$ & $c_{2}($ N.m.s $/ \mathrm{rad})$ \\
\hline 1 & 24.7 & 0.48 & 17.5 & 0.34 & 16.3 & 0.32 \\
\hline 2 & 27 & 0.53 & 18.6 & 0.36 & 18.7 & 0.37 \\
\hline 3 & 20.8 & 0.41 & 13 & 0.25 & 11.2 & 0.22 \\
\hline & $c_{2 \mathrm{~m}}$ & 0.47 & $c_{2 \mathrm{~m}}$ & 0.32 & $c_{2 \mathrm{~m}}$ & 0.30 \\
\hline
\end{tabular}

\section{Conclusions and remarks}

This study has shown that it is possible to characterize the stiffness and damping of the rubbers of TVD pulleys. Simple characterization tests have been set up. The tests can be carried out at different temperatures thanks to a hot air blower and a box that keeps the test rig at constant temperature.

The pulley to be characterized is fastened to a rigid frame and then depending on which rubber to be characterized the pulley or the additional mass ring are subjected to a tosional excitation realized by a tangent force. A frequency sweep excitation is performed. The accelerometers glued on the different parts of the pulley permit to obtain the frequency response function to the excitation. Then classically the resonance frequency and the damping ratio are determined.

The pulley decoupling rubber has a low stiffness and is quite sensitive to the temperature, particularly its damping which increases with the temperature. The additional mass rubber shows a small dependency on the temperature for the stiffness and damping. The values decrease with the increase of temperature.

The characterization study reported here can be applied to any other TVD pulley with additional mass and decoupling feature.

\section{References}

[1] H. Blanc, Dynamique des rotors en torsion: Étude des amortisseurs de torsion, Techniques de l'Ingénieur, ref. BM 5124

[2] L. Manin, G. Michon, E. Comble, R. Dufour, Détermination expérimentale des caractéristiques mécaniques de courroies de transmission: raideur et amortissement longitudinaux, module de flexion, Revue des Composites et Matériaux Avancés, Ed. Lavoisier 3 (2003) 317-326, doi:10.3166/rcma.13.317-326

[3] S.J. Hwang, N.C. Perkins, A. Ulsoy, R.J. Meckstroth, Rotational Response and Slip Prediction of Serpentine Belt Dirve Systems, ASME J. Vibr. Acoust. 116 (1994) 71-78

[4] G.W. Fan, T.C. Kraver, J.J. Shah, Complex modal analysis of a flat belt pulley system with belt damping and Coulomb-damped tensioner, J. Mech. Des., ASME 118 (1996) 306-311

[5] M.J. Leamy, N.C. Perkins, Nonlinear Periodic Response of Engine Accessory Drives With Dry Friction Tensioners, ASME J. Vibr. Acoust. 120 (1998) 909-916

[6] G. Michon, L. Manin, R. Dufour, Hysteretic behavior of a belt tensioner: modelling and experimental investigation, J. Vibr. Control 11 (2005) 1147-1158

[7] L. Manin, G. Michon, Entraînement par courroies striées. Partie 1. Architecture et comportement dynamique global, Techniques de l'Ingénieur, ref. BM5690, 2010, 16p 